\title{
On the Relationship between Organizational Socialization Tactics and Fresh Graduated New Comers’ Employment Quality
}

\author{
Liang Xiaowei \\ Management School of Wuhan University of S. \& T. \\ Wuhan, China \\ email: liangxiaowei@wust.edu.cn
}

\author{
Sun Xia \\ Management School of Wuhan University of S. \& T. \\ Wuhan, China \\ email:3198175419@qq.com
}

\begin{abstract}
Taking the fresh graduated new comers who, as career starters, are in the stage from their career exploration to establishment as the subject of this discussion, the mechanism of their employment quality formation is analyzed from the organizational socialization perspective based on current literatures. The relevant propositions and their testing model are put forward in order to better the empirical study of the issues, the organizational socialization tactics and their performances.
\end{abstract}

Keywords—career starter; organizational socialization tactics; employment quality

\section{INTRODUCTION}

An individual's organizational socialization can theoretically go through his or her whole career with the transition from one organization or role to another [1]. The new comers' turnover especially as one of the most vital indicators in their organizational socialization performances can not only reflects the resource cost and the expected organizational sustainable benefits but also heavily influences the employment qualities' formation of the fresh graduated career starters characterized by their successful student-professional role transition, professional satisfaction, perceived professional reward, perceived self-effectives in their career development, employment stability and so on [2]. Therefore, clarifying the new comers' employment quality formation mechanism from the organizational socialization scope is of innovation values to both organizational talent management practices and related theories.

The formations of the employment quality and the career success of the fresh graduated new comers are generally deemed to be vitally influenced by their organizational socialization process from their entry. But they can often be the group of the highest turnover with the organizational socialization failure. A recent investigation has been reported that the turnover rate of the fresh graduated new comers is over $45 \%$ in half year after their entry, in which the voluntary turnover takes the proportion of $88 \%$ with $65 \%$ of the organizational socialization factors as inducement [3]. The organizational socialization tactics are generally assumed the essential way to reach the employers' expected performances of the new comers. However, the present studies on the relationship between the tactics and the new comers' turnover as the quality indicator of employment stability are very few [4]. So, we shall take the fresh graduated career starters as the subject in this paper and propose based on reviewing current literatures an empirical research model by dividing the new comers' response to their organizational socialization tactics into two levels (e.g. organizational role identity and professional role identity), by which we hope to broaden the research scope of the mechanism of the organizational socialization's influences on the employment quality formation of this group of the new comers.

\section{The Position OF THE ORganizational SOCIALIZATION TACTICS' INFLUENCE ON THE Fresh GRADUATED NEWCOMERS' PERCEIVED EMPLOYMENT QUALITIES}

It is generally considered that the employment quality can reflect both the employees' job reward level and their psychological response embedded in the organizational situation [5]. Scholars summarize the quality factors into employed quantity, property and employees' expected realization such as satisfaction, perceived employment experience and their input-output level [6, 7]. Current studies on the new comers' employment quality factors focus on the description of quality indication and hierarchical indicator assessment system itself and less on the quality formation mechanism in their organizations [8]. Obviously, the new comers' organizational socialization can become the essential base on which their employment quality can be formed. It is generally thought that a newcomer's family and many inducements from the society his or her life embedded in can interact together as the forces to shape how his or her perceived employment quality is like but these inducements belong to the unchangeable (e.g. sexual, family factors) or uncontrollable (e.g. macro social factors) ones for the employers' organizations, in contrast to which the newcomers' organizational socialization tactics as the usual HRM practices can directly influence the newcomers' adjustment to their job or career profession. 
So their perceived adjustment levels can naturally imply perceived employment qualities and the newcomers' organizational socialization process can form the organization's initially most manageable way by which the fresh graduated newcomers' perceived employment qualities are generated. Then we can put forward the proposition 1: the fresh graduated newcomers' perceived attributions of the employment quality are more sensitive to the organizational socialization tactics than to the factors out of the organizational boundary.

\section{THE RELATIONSHIP BETWEEN THE NEWCOMERS’ ORGANIZATIONAL SOCIALIZATION PERFORMANCES AND THEIR PERCEIVED EMPLOYMENT QUALITIES}

The validity of the organizational socialization laid on the newcomers' perceived employment quality can be felt embodied in their organizational socialization performance, based on which the relationship between them can be grasped from two scopes: understanding the essence link and the transferability from the newcomers' perceived employment qualities to their organizational socialization performances and grasping the identity discrepancy of their perceived professional role and job position role and attribution tendency caused with the organizational tactics especially for the fresh graduated new comers in their career or professional exploration stage [2]. In the former scope, richer studies existed on the employment quality factors [5,6,7,8] can be summarized into Table I.

TABLE I. CURRENT EMPLOYMENT QUALITY INDICATOR SySTEM

\begin{tabular}{|c|c|c|c|}
\hline Scope or Level & Objective & Subjective \\
\hline Social & employment rate, average reward & perceived fair employment & Omnibus of the ob. and sub. indicators \\
\hline Career or professional & professional reward, professional turnover & career or vocational satisfaction & mix of the ob. and sub. indicators \\
\hline Individual & job reward, voluntary turnover & job satisfaction, job turnover intention & mix of the ob. and sub. indicators \\
\hline
\end{tabular}

For the latter scope, we can recognize the transferability between the newcomers' perceived employment qualities and their organizational socialization performances by comparing the same dimension of the assessment indicators of the both (see Table II). It can be seen in Table II that the indicator dimension connotation for appraising the newcomers' organizational socialization performances and their perceived employment quality factors can reflect the newcomers' perceived substituted conversion effect from the former to the latter performance indication in the same dimension. Then we can put forward the proposition 2: the stronger the newcomers as career starters feel their acquired organizational socialization performance, the higher their perceived employment qualities are.

TABLE II. CONVERSION OF THE INDICATORS BETWEEN SOCIALIZATION PERFORMANCE AND EMPLOYMENT QUALITY

\begin{tabular}{|c|c|c|}
\hline Scope or Dimension & Socialization Performance & Employment Quality \\
\hline Satisfaction & Job satisfaction & Professional satisfaction \\
\hline Reward & Job reward satisfaction & Profession reward satisfaction \\
\hline Perceived achievement & Perceived job achievement & Perceived professional achievement \\
\hline Safety and health care & Job safety and stress & Professional safety and stress \\
\hline Role identity & Perceived job role and position & Professional role expectation \\
\hline Sustainable employment & job promotion potential & career advancement potential \\
\hline Social contribution & Job performance/ achievement & Professional achievement \\
\hline Employment stability & Job turnover & Professional turnover \\
\hline
\end{tabular}

The ultimate goal of the organizational socialization strategy is generally assumed to make the newcomers get them adjusted to the expected organizational performance and finally transformed from the outsiders to the insiders of their organizations [9]. But the newcomers can not be only seen as the atomic individuals in their job life and can have the social links embedded in their professional community that can exist in and across their organizational boundary so that the newcomers can be induced to have the responses of not only how to adjust themselves to the expected 'the insider' roles but their perceived successful professional roles and relevant choice decisions during their organizational process situation [10]. The fresh graduated employees in their career exploration stage may response more sensitively to the latter [11]. Then we can put forward the proposition 3: the larger the proportion of the professional socialization factors in the newcomers' organizational socialization process, the higher the newcomers' perceived employment qualities are induced by the socialization tactics.

\section{THE INFLUENCING MECHANISM OF THE ORGANIZATIONAL SOCIALIZATION ON SHAPING THE NEWCOMERS' PERCEIVED EMPLOYMENT QUALITIES}

The classic organizational socialization theory takes it for granted that the whole process of the newcomers' organizational socialization is built up around their organizational role transformation, learning adjustment, getting stable accepted job performances and becoming in the end the 'organizational insiders' [12]. Therefore, we can identify the influencing mechanism of the organizational socialization in shaping the newcomers' perceived employment qualities form the organizational socialization tactics, core media effective factors, key moderators, and possible expected organizational performances. 


\section{A. The Organizational Socialization Tactics}

The organizational socialization tactics are usually assumed as the effective HRM practices to promote the members' expected organizational performances in their different career stages. VanMannen and Schein [1,12] theoretically summarized the tactics into six types widely cited in the literature (see Table III), and later, Jones further abstracted them into two kinds: institutional organizational socialization tactics and individual organizational socialization ones, in which the former is characterized of the managers' maintaining existed organizational culture system, choosing more formal and settled tactics and the newcomers' more passively accepting their job roles, and the latter is of laying more focuses on the newcomers' individual difference influence on reaching expected organizational performances and their active role identification[13]. As far as the fresh graduated employees in their professional exploration stage are concerned, their perceiving to all kinds of the organizational tactics can contain not only the responses to the expected organizational role identity (ORI) but their professional socialization ones (e.g. their perceived vocational prestige, vocational position, vocational rewards and so on) because of their embedded living way in their professional society across their organizational boundaries $[2,8]$. The classic kinds of the organizational socialization tactics can therefore be extended into a more comprehensive system covering professional role identity (PRI) promotion factors which exist impersonally but often ignored in the literature. Then we can put forward the proposition 4: the professional socialization factors exist inevitably in the organizational socialization tactic system, from which the stronger the level newcomers' perceived their professional role identity are, the higher level their perceived employment qualities induced by the socialization tactics.

TABLE III. Extended Organizational Socialization Tactics System

\begin{tabular}{|c|c|c|}
\hline \multirow{2}{*}{ Tactics and Factors } & Institutionalized Tactics & Individualized Tactics \\
\hline & ORI promotion & ORI promotion \\
\hline \multirow{2}{*}{ Situation factors } & Collective & Individual \\
\hline & Formal & Informal \\
\hline \multirow{2}{*}{ Content factors } & Fixed & Variable \\
\hline & Sequential & Random \\
\hline \multirow{2}{*}{ Social factors } & Serial & Disjunctive \\
\hline & Investiture & Divestiture \\
\hline
\end{tabular}

\section{B. The Core Effective Media Factors and the Key Moderating Factor}

It is deemed that expected organizational socialization performances of the newcomers can be effectively reached with the tactics though tree paths (direct path, media variable path and mixed paths) [4], in which there are significant differences of the path effectives to the newcomers in their different professional stages [2]. The fresh graduated career starters' learning is assumed to be dominating in successful transformation of their student-job role identification so that their learning can be the key or main path link to connect the organizational socialization tactics' efficiencies to the newcomers' expected organizational performances $[12,14]$. And their perceived organizational role identity can be apparently extended to their perceived career or professional role identity for their embeddedness in both their organization and professional society. Then we can put forward proposition 5a: the new comers' organizational socialization performances can be reached though their learning perceived job roles to form their organizational identity, and the higher level the identity is, the higher their organizational socialization performances are.

And proposition 5b: the new comers' organizational socialization performances can be reached though their learning perceived job roles to form their career or professional identity, and the higher level the identity is, the higher their career or professional socialization performances are.

It is theoretically assumed that there exist some key moderators closely related with the newcomers' socialization traits (e.g. their career cycle trait) before their entry of the organization, which can significantly moderate the newcomers' expected organizational socialization performances [15]. The Chinese fresh graduated new comers usually are in the period of transition from career exploration to career establishment divided by Super [11]. For operational measurement of this process, we can define two kinds of the variable indicators: the level of career exploration trend and the level of career establishment trend, and assume that the stronger the career exploration trend level, the lower level the newcomers' professional maturity and the stronger the career establishment trend level, the higher the newcomers' professional maturity. Then we can put forward proposition 6a: the newcomers' maturities can mainly influence their learning performance levels by interacting with perceived organizational socialization tactics, and the higher their maturity levels are, the higher levels the newcomers' perceived organization identity and professional identity. And proposition 6b: the newcomers' maturities can mainly influence their organizational socialization end performance levels by interacting with their perceived organizational socialization tactics, and the higher their maturity levels are, the higher levels of the newcomers' perceived organizational socialization end performances.

\section{Organizational Socialization Performance}

The classic organizational socialization theory takes it for natural that the expected organizational socialization performances belong to the effective responses from the newcomers to the socialization tactics put on them, the assessment contents of which are multi-dimensions and can divided into the process performances (e.g. the learning performance: organization identity as media 
factor of the whole process), the end result performances (e.g. the distant behaviors: job performance and turnover) [12, 4]. But the classic performance system doses not include the career view-based performance dimensions the newcomers simultaneously perceive from the expected organizational roles in the process. So we can extend this perceived performance dimensions to more comprehensive ones including the newcomers' career or profession-based view socialization performances that impersonally exist in their responses and behaviors during the process and are of the nature of their employment quality indicators (see Fig. 1). Then we can put forward proposition 7: the new comers' perceived organizational socialization performances induced by the tactics in their organizational socialization process can be divided into two kinds: the expected ones by the organization and the caree $r$ view-based ones by the newcomer themselves, in which the former ones are closely associated with the new comers' organization identity and the latter ones with their career or professional identity.

\section{SUMMARY}

It can be seen that the current literature on the relationship between the organizational socialization tactics and the new comers' expected performances often ignore their career or professional socialization responses induced though their perceived position roles in their employers' organizations for the classic organizational socialization theory and practice usually lay stress on how to effectively transform the new comers into the insiders from the outsiders though the socialization tactics. So it may result in ineffective explanation or prediction on the phenomenon of the new comers' (especially the Chinese fresh graduated career starters') higher turnover during their organizational socialization process.

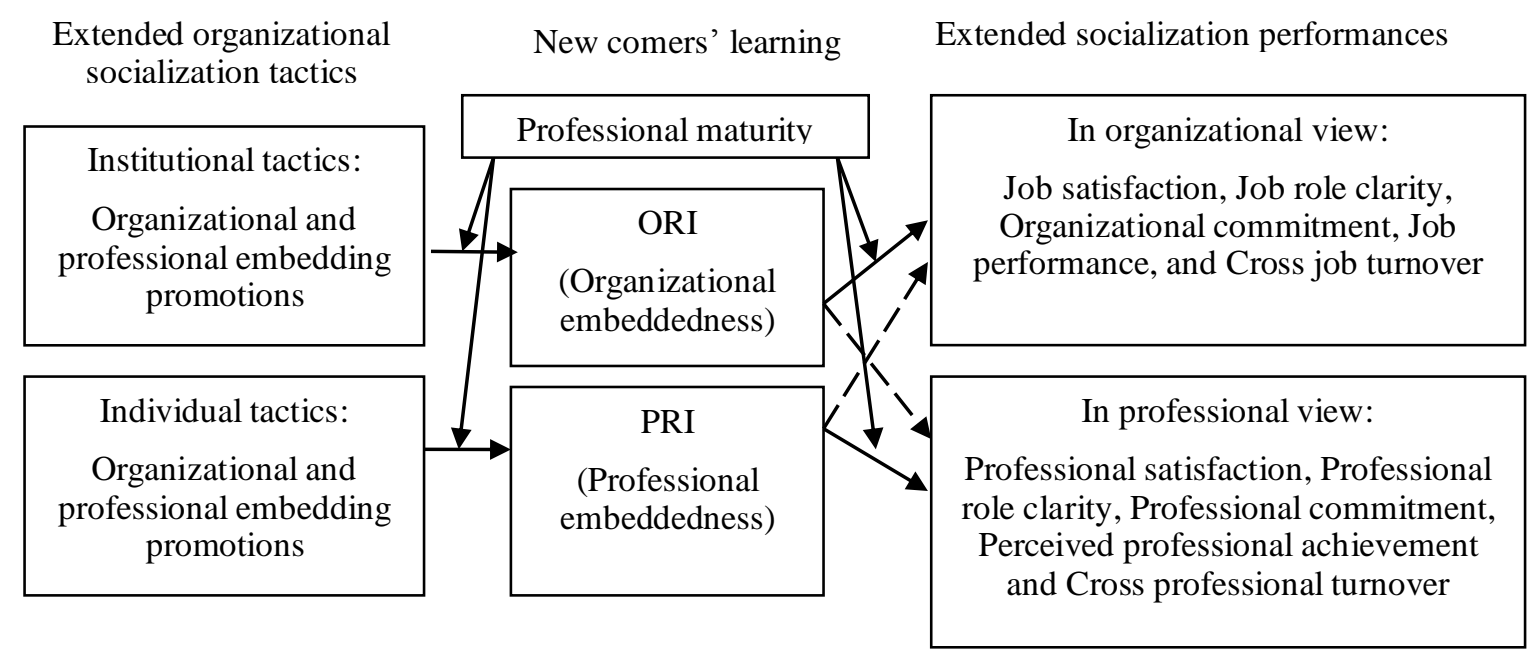

Fig. 1. The influence of the socialization tactics on the new comers' employment qualities (dashed lines denote likely correlations among the variables)

We can logically summarize the possible path relationships among the variables in the propositions above into an empirical research model (Fig. 1 above). The advantages or contributions of the model for future study can at least lie in three aspects: (1) This model lays focus on the fresh graduated new comers in their professional exploration stage, which may likely strengthen the effective explanation or prediction of their behaviors during their organizational socialization process; (2) The new comers' performances induced by the organizational socialization tactics are extended to two sides: expected job role identity in the employer's organization and new comers' perceived career or professional role identity, which is not only better in effectively testing the propositions above but also in discovering or clarifying the mechanism of the socialization factors in leading the career starters' higher turnovers (e.g. the higher turnover might be caused by the new comers' lower perceived career or professional role identity yet still not low position role identity in the employer's organization, which is hardly testable in the traditional model); and (3) The model may help in diagnosing the organizational socialization tactics and promoting sustainable growths of both the organization and the newcomers.

\section{REFERENCES}

[1] John Van Maanen, and Edgar H. Schein, “Toward a theory of organizational socialization,” Research in Organizational Behavior, 1, pp. $209-264,1979$.

[2] Ng, Thomas W. H., and Daniel C. Feldman, “The school-work transition: a role identity perspective,” J. of Vocational Behavior, vol. 71, pp. 114-134, 2007.

[3] Mycos (China), An investigation on 12'-14' Chinese university students' employment on http://www.jyb.cn/job/jyzd/201506/t20150602_364654.html, 2015.

[4] Allen, David G., "Do organizational socialization tactics influence newcomer embeddedness and turnover?" J. of Management, vol. 32, pp. 237-256, 2006 
[5] Lucie D, and Christine E., "Monitoring employment quality in Europe: European employment strategy indicators and beyond," International Labor Review. vol. 147 pp. 239-343, 2008.

[6] Zhao Ming, and Gu Yongyuan, "A Review on the university graduates' employment quality,” J. of Neijiang Normal College (Chinese), 11, 112-114, 2012.

[7] Qiao Shan, and Li Hong, "On the university graduates' employment quality," Education and Teaching Forum (Chinese), 16, pp. 1-2, 2015. .

[8] Xu Li, "A study on the relationship between the university graduates' employment quality and their social capital," J. of South-Central University for Nationalities (Chinese), 9, pp. 85-86, 2010.

[9] Wang Yanfei, and Zhu Yu, "Organizational socialization theory and its research development," Foreign Economics \& Management (Chinese), vol. 28, 15-21, 2006.

[10] Ng, Thomas W. H. and Daniel C. Feldman, "Organizational embeddedness and occupational embeddedness across career stages," J. of Vocational Behavior, vol. 70, 336-351, 2007

[11] Super, Donald E., "A Life-Span, Life-Space Approach to Career Development," J. of Vocational Behavior, vol. 16, pp. 282-298, 1980.

[12] Ashforth, B. E., David M. Sluss, and Alan M. Sakes, "Socialization tactics, proactive behavior, and newcomer learning: integrating socialization model," J. of Vocational Behavior, vol. 70, pp. 447-462, 2007.

[13] Jones G. R., "Socialization tactics, self-efficacy, and newcomers adjustments to organizations," Academy of Management J., vol. 29, pp. 262-279, 1986.

[14] Saks A M, and Ashforth B. E., "Socialization tactics and newcomer information acquisition," International J. of Selection and Assessment, 5, pp. 48-61, 1997.

[15] Chao G T, and Gardner P. D., “Organizational socialization: Its content and consequences,” J. of Applied Psychology, Vol. 79, pp. 730-734, 1994. 